\title{
UMA RESPOSTA SOBRE O QUE É O AMOR PLATÔNICO A PARTIR DA RELAÇÃO ERÓTICA ENTRE SÓCRATES E ALCEBÍADES NO SIMPÓSIO DE PLATAO.
}

\section{An answer on what is platonic from the relationship between Socrates and erotic Alcibiades in Plato's symposium.}

Felipe Gustavo Soares da Silva ${ }^{1}$

RESUMO: O amor em Platão ao contrário do que é normalmente concebido pelo senso comum, como abstrato e imaginário, tem um aspecto amplo e bastante prático. O presente trabalho aborda a concepção de amor platônico para mostrar a partir da experiência filosófica vivida por Sócrates e Alcebíades descrita no Banquete de Platão, como o amor representava na antiguidade uma prática educativa que envolvia duas pessoas.

Palavras-chave: Amor Platônico; Paideia; Pedagogia.

ABSTRACT: The love in Plato contrary to what is usually conceived by common sense, as abstract and imaginary, has a large and very practical aspect. The present work approach the concept of platonic love to show from the philosophical experience lived by Socrates and Alcibiades described in Plato's Symposium, how love were represented in antiquity an educational practice involving two people.

Keywords: Platonic love; Paideia; Pedagogy.

\section{INTRODUÇÃO}

Ora, este trabalho tem como objetivo responder o próprio título na expectativa de tecer uma resposta, ao senso comum que normalmente reconhece no clichê "amor platônico" uma teoria de um amor, imaginário, inalcançável, e ainda, de caráter estreitamente homossexual. Para tanto, parece-nos que há em Platão uma teoria do amor, que difere da concepção do senso comum, sendo portanto, necessário demonstrar a noção filosófica do conceito de amor e ainda mais, demonstrar a finalidade prática desse amor sugerido por Platão.

\footnotetext{
${ }^{1}$ Mestre em Filosofia pela UFPE. Especialista em Educação, pobreza e desigualdade social pela UFPE.
} 
No senso comum é corriqueiro ouvirmos pelas pessoas, certos comentários referentes aos seus relacionamentos afetivos, sejam fracassados, correspondidos ou vividos a partir de experiências singulares associadas à um clichê, amor platônico. Normalmente, usa-se esse clichê para definir um amor que seria inacessível, difícil, não correspondido etc. Parece-nos que a raiz desse pensamento está no fato de que o pouco que se conhece Platão pelos manuais escolares, por revistas e por frases comumente a ele atribuídas é o suficiente para defini-lo como o filosofo do mundo das ideias, mundo este do inacessível, das coisas irreais, repletas de fantasia, ilusão e distantes de verdade. Costuma-se ainda chamar de "amor platônico", as relações entre homens do mesmo sexo ou relacionar o amor platônico às relações pederásticas. Parece-nos que as mais diversas tentativas de dizer o que é o amor platônico caem no mesmo erro: o de dizerem ser esse amor algo distante do real ou um amor sexualizado, ainda que dirigido para o sexo oposto.

Desta forma, torna-se relevante, a partir da leitura do próprio Platão, demonstrar que o conceito de amor em Platão é amplo e prático contribuindo, inclusive, pela sua finalidade, para falarmos do processo educativo na antiguidade. Aqui defendemos que há uma teoria do amor em Platão, que manifesta-se explicitamente de maneira pedagógica e formativa e que não pode ser reduzida a mero clichê ou uma mera frustação ou irrealidade, tentaremos então demonstra-la na tensão existente nos discursos entre Sócrates e Alcibíades, no Simpósio, que a nosso ver, contribui de maneira singular, pelo conceito de Eros, para nos falar em que consiste o amor em Platão, para que se dirige e qual sua principal dimensão, que aqui defenderemos como pedagógica, visto que os dois discursos são relatos de aprendizado, um positivo e outro fracassado.

O tema do amor em Platão é estudado por autores importantes tais como Robin $^{2}$, Dover, ${ }^{3}$ Michel Foucault ${ }^{4}$ e Rowe,${ }^{5}$ sempre voltados para o exame do amor como uma lacuna se ser per pesquisada visto, partir da relação entre Sócrates e Alcebíades, trazer-nos algo muito prático de nossa vida: a complexidade das

\footnotetext{
${ }^{2}$ ROBIN, Léon. La theorie platonicienne de l'amour. Paris, PUF, 1964.

${ }^{3}$ DOVER, K. J. A homossexualidade na Grécia antiga. Trad. L. S. Krausz. São Paulo: Nova Alexandria, 1994.

${ }^{4}$ FOULCALT. M. História da sexualidade: vol.2 O uso dos prazeres. Ed. Graal, São Paulo, 2010.

${ }^{5}$ ROWE, C. "The Symposium as a Socratic Dialogue", in Lesher et alii. 2006.
} 
relações amorosas em que nos envolvemos e, em que medida, essas relações são frutos de uma civilização ${ }^{6}$ e representam um modo de vida do próprio homem. ${ }^{7}$

\section{O AMOR NA OBRA PLATONICA}

Como na maioria dos diálogos que chegam até nós através de Platão, os temas do amor na obra platônica tem sua conclusão aporética, não sendo portando possível de se afirmar o que é o amor em Platão mas apenas relatar e comparar as afirmativas. As relações de amor e de amizade são os campos do problema: ora, a primeira coisa que constatamos ao iniciar nossa pesquisa é que, Platão é dito o filósofo do Eros. ${ }^{8} \mathrm{E}$ concordamos em todo nosso trabalho com essa afirmativa, afinal, filósofo e atividade são, não por acaso, etimologicamente, pessoa e atividade, respectivamente, guiados por um 'desejo' e um 'amor' à Sabedoria, que no Simpósio nosso autor denomina a partir de 'Eros' que por sua vez submete o homem às relações e aos efeitos que derivam desse desejo. Podemos afirmar que a atividade filosófica consiste numa atividade erótica, onde, assim como Eros, o filosofo, carente, busca aquilo que não possui: a sabedoria. Porém surge a necessidade de diferenciar amor e amizade, ou pelo menos esclarecer os dois conceitos, para podermos avançar na delimitação do problema. O estudo de Allam Bloom aparece como esclarecedor desse problema ao apresentar a amizade ligada ao conceito de útil visto diferindo-a do conceito de Bom: O bom basta-se contemplar, o útil tem-se que possuir visto sua utilidade. ${ }^{9}$ Ainda segundo M. Montenegro

(...) talvez a maior diferença entre Eros e Philia resida no fato de que esta implica necessariamente uma reciprocidade, enquanto aquele pode perfeitamente prescindir de correspondência. Aliás o caráter prescindível da reciprocidade concernente ao Eros parece favorecer a emergência de uma relação de assimetria que, na cultura grega do período clássico, torna-se canônica, fazendo-se caracterizar exemplarmente nas relações pedagógicas entre mestre e discípulo. Nesse contexto, o mestre assume o papel do amante(erastes) enquanto o discípulo toma o lugar do amado (erônemos). ${ }^{10}$

\footnotetext{
${ }_{7}^{6}$ DOVER, 1994.

${ }^{7}$ HADOT, P. Ejercicios espirituales y filosofia antigua. Siruella, Madri. 2006.

${ }^{8}$ MONTENEGRO, M. A.P. Eros e Philia na filosofia platônica. Archai, n.13 jul-dez, 2014. p.121-129

${ }^{9}$ Cf. BLOOM, A. Love and Friendship. New York, Simon \& Schuster. 1993

${ }^{10}$ MONTENEGRO, M.A.P. 2014. p.123.
} 
Ora, o tema do amor em Pode ser analisado da seguinte maneira: Aqui abordamos a importância de observarmos o problema do amor na teoria platônica, para depois, mais a frente, podermos esclarecer a sua essência. O Lysis, irá tratar a questão da amizade afim de esclarecer os mais diversos aspectos que estão ligados a esse conceito. Apesar dessa pretensão, a obra não esclarece exatamente o que seria a amizade, conforme vemos na despedida de Sócrates ao fim do diálogo: "nossos ouvintes irão embora comentando que nós, que temos a pretensão de ser amigos - e eu me coloco como tal em relação a vós - não fomos capazes de descobrir o que é um amigo." ${ }^{11}$ Parece-nos que o diálogo apesar de sugerir algumas noções sobre o que seria a amizade, não a define, o que caracteriza o diálogo a nosso ver, como aporético de forma que ao entrar em contato com o texto, sentimos ainda maior a necessidade investigar a temática. De qualquer forma, observamos que no texto, o termo usado para denominar o amor não é Eros mas philia ( $\varphi$ ı $\lambda i ́ \alpha)$ o qual remete diretamente à etimologia da palavra Filosofia ( $\left.\Phi_{\perp} \lambda \circ \sigma+\sigma o \varphi i ́ \alpha\right)$. O termo philia é utilizado na obra para significar as relações de amizade em relação à reciprocidade e valor moral e comumente interpretado como a amizade ou como o "amor entre amigos". Longe desta discussão, acreditamos que o caráter aporético do Lysis é na verdade uma introdução ao pensamento platônico sobre o que é o amor, visto que, ao reconhecer no final do diálogo que é difícil definir o que é a Philia, parece que, temos uma insinuação que, de fato, as coisas envolvendo o amor, seja de qualquer forma, são difíceis até mesmo de serem definidas.

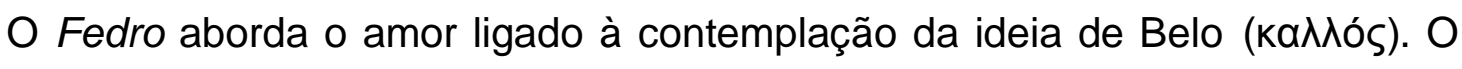
amor é associado à uma espécie de loucura divina e se instalará no filósofo devido à sua aspiração à beleza, mas inspirada pelos deuses para a felicidade do homem. Sem dúvida, esta obra nos oferece uma visão metafísica e bem salutar sobre o que Platão sugere acerca do porquê do homem apaixonar-se. $O$ termo grego para denominar o amor na obra é Eros ("E $\rho \omega \varsigma$ ) que é usado para definir o amor como um desejo. ${ }^{12} \mathrm{~A}$ obra utiliza-se do recurso do mito da parelha ${ }^{13}$ para mostrar o que é a alma do homem, e toda sua complexidade. Só o amor à ideia de Belo é que tornará possível à alma que possa criar asas e retornar ao mundo das ideias. A nosso ver, a obra também introduz a questão do amor em Platão sobretudo já introduzindo-o a

\footnotetext{
${ }^{11}$ PLATÃO. Lys. 223b

12 PLATÃO. Phaid. 237e

${ }^{13}$ PLATÃO. Phaid 246a
} 
partir de Eros ('E $\rho \omega \varsigma$ ) que irá relacioná-lo na complexidade do desejo e indicará um meio concreto para que o homem possa atingir o domínio do desejo e sua devida direção para a contemplação da ideia de Beleza, que é a Filosofia. A obra destina-se a mostrar muito mais as partes da alma e sua complexidade do que a complexidade exclusivamente de Eros, que será descrito no Simpósio.

\section{A NOÇÃO DE AMOR POR EROS NO SIMPÓSIO}

Há na relação amorosa de Sócrates ${ }^{14}$ e Alcibíades ${ }^{15}$, uma dimensão pedagógica a ser examinada, e acreditamos que, a partir de Eros e do estudo de seus efeitos no ser humano, pode-se demonstrar como, no amor há uma necessária dimensão pedagógica.

O clássico estudo de Gregory Vlastos acusa o amor ou o Eros platônico de uma falta de $a m r^{16}$, de uma impessoalidade, por não dirigir-se ou pelo menos fugir do amor ao outro, ou seja, não se dirige exatamente para a pessoa e concordamos, pois Eros sugere que dirige-se a uma dimensão muito mais profunda e distante do meramente corporal. Para tentar responder o que é o amor em Platão, parece-nos muito mais útil utilizarmos a prática descrita no Simpósio, pois, além de ser uma obra reflexiva, fruto da dialética, e carregada por um sentido, a nosso ver, pedagógico, a obra traz experiências concretas sobre o amor, atingindo, na tensão existente nos discursos de Sócrates-Diotima e Alcebíades, o auge do conceito pedagógico, pelo relato dos dois aprendizados: Ademais, a obra nos oferece tratar sobre o amor a partir do conceito de Eros, a nosso ver muito mais rico de significado e de conteúdo para definirmos a dimensão humana do amor.

\section{O APRENDIZADO DE SÓCRATES}

\footnotetext{
${ }^{14}$ Sócrates aparece como personagem principal dos diálogos platônicos: segundo alguns autores, Platão simplesmente testemunha o que aprendeu e viveu com Sócrates, para outros estudiosos, Platão faz uma defesa do mestre. Historicamente, Sócrates é um dos primeiros filósofos, conhecido pela sua filosofia que consistia basicamente num constante exame da própria vida.

${ }^{15}$ Alcebíades, personagem importante no diálogo Simpósio, mas aparece também em outros diálogos platônicos. Jovem com pretensões políticas mas que tinha problemas na hora de trabalhar a si próprio, de educar-se, de examinar a própria vida. Seu mestre, segundo relatos do próprio Simpósio, é o próprio Sócrates, ou seja, o melhor dos mestres, o que não garantira exatamente o bom sucesso do jovem na Filosofia. Recomendamos ao leitor fazer uma leitura do diálogo Alcebíades primeiro, afim de conhecer um pouco mais da problemática da educação do jovem.

${ }^{16}$ VLASTOS, Gregory. The Individual as an object of Love in Plato, in. Platonic Studies, Princeton, 1973.
} 
Ora, o Simpósio revela a educação de Sócrates, conforme ele mesmo testemunha, aprende da sacerdotisa Diotima, noções sobre o amor, sobre Eros. O motivo da escolha de Diotima é segundo, De La Torre pelo fato de que

O recurso à personagem feminina permite a Sócrates não apenas atenuar as opiniões precedentes (especialmente a de Agatão) e também proceder a uma descrição surpreendente de Eros, tanto no referente a sua origem (certamente elaborado entre poros e Penia pelo motivo do banquete ser também em honra ao nascimento de Afrodite), como a sua natureza (um daimon intermediário) como (muito especialmente) a sua definição e finalidade. ${ }^{17}$

A sacerdotisa Diotima, irá tratar de definir a natureza do deus a partir de sua genealogia; isto será fundamental na hora de encontramos a refutação ao discurso de Agatão, onde o amor seria autossuficiência, mas na verdade, mostra-nos a sacerdotisa, é falta e carência: o pai de Eros vive a filosofar, é corajoso, sua mãe, diz-se que é carente e por isso procurou a Poros, para alcançar o meio de alcançar a euporia ${ }^{18}$ ou seja, de superar-se. Assim é Eros, desejante de superar sua carência.

Torna-se importante dizer que, em segundo lugar, temos no discurso a caracterização do amor como um caminho a ser percorrido em direção à ideia de Belo, em outras palavras, um caminho para um amor ordenado. As noções são atribuídas por Sócrates como fruto do aprendizado com a sacerdotisa Diotima, a qual possui um caráter dessexualizado e distante das relações corpóreas. ${ }^{19} \mathrm{O}$ caminho do amor a ser percorrido é chamado acético ou scala amoris: ${ }^{20}$ Essa concepção é fundamental para falarmos do amor aprendido por Sócrates, pois a scala amoris é o ponto culminante do discurso da sacerdotisa, que irá tratar sequencialmente dos objetos para quais Eros irá se dirigir até alcançar a ideia de beleza. M. Nussbaum define a scala amoris como um processo acético em que

Em cada estágio da acese, o aspirante ao amor, por seu mestre, vê relações entre uma beleza e outra, reconhece que essas belezas são comparáveis e intercambiáveis, diferindo apenas em quantidade. Ele sai com uma estima proporcionalmente diminuída, embora não plenamente extinta, por aqueles que anteriormente ele

\footnotetext{
${ }^{17}$ DE LA TORRE. Emílio Suárez. En torno al banquete de Platón. Humanitas vol. LIV (2002) 63-100 P.89

${ }^{18}$ FERRARI. F. 2012. P.67

${ }^{19}$ BRĖS, Yvon. La Psychologie de Platon. 2 ed. Paris: PUF,1973.

${ }^{20}$ FERRARI. F. 2012. P. 68
} 
menosprezava. Sua visão é ampliada de modo a incluir a beleza ou os valores da lei, instituições ciências. ${ }^{21}$

Ademais, estudando a relação entre Eros e seus objetos, encontramos a seguinte conclusão sobre a scala amoris:

Ora, a clássica ascese erótica do amor platônico, conforme já descrevemos como a correta orientação nas coisas do amor, não é outra coisa senão a mudança de alvo de Eros que renovando seus objetos, tal como uma dýnamis, produz novos e diferentes capacidades e efeitos na alma daquele que é possuído pelo amor. Ao cambiar de orientação, Eros, como uma dýnamis, transforma o efeito que produz no coração dos homens. ${ }^{22}$

Desta forma, podemos encontrar o amor de Sócrates, aprendido da Sacerdotisa como um ordenado, voltado para o intelectual, para a superação da própria ignorância, sendo, portanto, o ponto final da escala acética do amor. Esse será o segredo do sucesso da educação de Sócrates por Diotima. Admitimos que esta ideia configura-se como a mais importante lição que o diálogo traz para dizer o que seria verdadeiramente o amor em Platão: a ideia de afastar-se do corpo e voltarse para o intelectual resume, de fato, o tema central do discurso, onde, busca-se primeiramente aquilo que se falta e este é o impulso que dá sentido ao amante a procurar o que mais proximamente ama, depois; busca-se através de uma espécie de escala, ou graus, ou ainda superação de etapas, frutos de exercícios práticos, progredir no amor afim de purifica-lo de tudo que for sexual para alcançar o intelectual, para alcançar o verdadeiro amor, deixa-se o corpo gradativamente, apesar de não se prescindir dele, para poder chegar-se à ideia perfeita da Beleza e Sabedoria.

\section{O NÃO APRENDIZADO DE ALCEBÍADES}

A cena da fala de Alcebíades mostra seu mestre interessado apenas no progresso do jovem, o jovem, por sua vez, confunde e compromete a si mesmo, e dirige o amor aprendido, pelo menos aprendido em tese, para o corpo de Sócrates, desvirtuando a verdadeira noção do amor ensinado pelo mestre.

\footnotetext{
${ }^{21}$ NUSSBAUM, M. 2019. p.158

${ }^{22}$ ARAÚJO JUNIOR. A. B. 2013. P. 63 
Aprofundando a fala de Alcebíades e a trazendo para o tema deste trabalho, o relato das virtudes de Sócrates mostra o exemplo prático ensinado pelo mestre de seguir tão somente a razão e não ceder a impulsos de desejos inferiores, como parece Alcebíades estar dominado pelas próprios apetites, ao entrar embriagado na casa de Agatão $^{23}$, e ao mostrar-se frustrado pela tentativa de dormir ao lado de Sócrates afim de satisfazer os próprios desejos. ${ }^{24}$

Sócrates aparece no Simpósio como mestre de Alcibíades. Mas é o discurso do jovem político que nos revela a intimidade da relação: O discurso de Alcebíades no seve primariamente, para mostrar a integridade moral de Sócrates, afinal, o testemunho do discípulo mostra um mestre fiel as regras tão somente pedagógicas da pederastias, e que inclusive, contrariavam algum tipo de envolvimento sexual. Com isso respondemos a uma primeira questão, que não há no amor em Platão' uma (necessária) relação homossexual mas, pelo contrário, busca-se sempre um amor que distancie-se do corpóreo.

A fala de Alcebíades nos remota a um elemento que pode ser introduzido pelas falas de M. Nussbaum: o papel do mestre, ou do amante, no processo formativo-pedagógico de seu amado. Segundo a autora,

Há algumas verdades sobre o amor que podem ser aprendidas
somente através da experiência de uma paixão particular própria. Se
se pede a alguém que ensine essas verdades, seu único recurso é
recriar essa experiência para o ouvinte: contar uma história, apelar à
sua imaginação e sentimentos pelo uso de vívida narrativa. Imagens
são valiosas nessa tentativa de dizer o público compartilhar a
experiência, sentir, do ponto de vista interno, como é ser aquilo. A
comparação de Sócrates com a estátua de Sileno, por exemplo, faz
com que o ouvinte apreenda esse homem que não lhe é intimamente
conhecido, e pela comparação dele com algo que é parte da
experiência cotidiana, torna disponível ao ouvinte um pouco do
sentimento cômodo que é querer e de querer conhece-lo. ${ }^{25}$

As palavras de Nussbaum nos sevem de aparato para examinarmos a questão sobre o modo da prática do ensino sobre as coisas, aqui, referentes ao amor. Alcebíades teve um dos melhores mestres possíveis, senão o melhor, mas parece que a forma que ele aprendeu a amar foi absolutamente diferente: sendo iniciado a amar coisas belas, e na ascese do amor, à ascender ao amor pelo Belo,

\footnotetext{
${ }^{23}$ PLATÃO, Symp. 212c

${ }^{24}$ Symp. $219 \mathrm{e}$

${ }^{25}$ NUSSBAUM, Martha C. A fragilidade da bondade. Fortuna e ética na filosofia grega. Martins fontes, São Paulo, 2009. p.163
} 
parece ter se apegado ao mais fácil, ao amor corporal. A situação revela que, há no aprendizado a experiência individual de cada um, a forma como cada uma experiência o conteúdo ensinado. Alcebíades experimentou o amor de vários outros mestres, mas como ele mesmo diz "nada para mim é tão importante como cuidar, com o maio empenho, do meu aperfeiçoamento, sendo certo que nesse particular ninguém me poderá ser mais útil do que tu." ${ }^{26}$

Alcebíades tinha ainda, segundo Romilly, todos os dons e meios necessários para um sucesso em sua vida política ${ }^{27}$ : Tinha dotes intelectuais, tinha Beleza, nobreza e principalmente um dos melhores mestres possíveis ${ }^{28}$, senão o melhor, mas parece que a forma que ele aprendeu a amar foi absolutamente diferente: sendo iniciado a amar coisas belas, e na ascese do amor, à ascender ao amor pelo Belo, parece ter se apegado ao mais fácil, ao amor corporal, ao amor do senso comum. A situação revela que, há no aprendizado a experiência individual de cada um, a forma como cada um experimenta o conteúdo ensinado. Alcebíades experimentou o amor de vários outros mestres e reconhece a superioridade de Sócrates "nada para mim é tão importante como cuidar, com o maio empenho, do meu aperfeiçoamento, sendo certo que nesse particular ninguém me poderá ser mais útil do que tu." ${ }^{29}$ Mas não aprende exatamente o que seria o amor verdadeiro e a ser praticado. Apaixona-se por Sócrates e a seu corpo deseja. Eis a grande questão, porquê Alcebíades não aprende o verdadeiro amor?

Para Sócrates, Alcebíades pensa que o mestre tem o poder de aperfeiçoa-lo mas não é bem assim. O próprio homem tem o dever e a tarefa de trabalhar no próprio aperfeiçoamento, ainda que, num contexto de uma educação pederástica, o outro como mestre pode favorecer esse trabalho de auto aprimoramento pelo exemplo e pelos ensinamentos mas não por um trabalho unilateral do mestre sobre o discípulo.

\section{A INVERSÃO DO AMOR: O ERRO DE ALCEBÍADES E OS PERIGOS DE EROS}

O amor de Sócrates e Alcebíades é um amor sujeito a diversas interpretações, dentre elas, a dimensão que aqui trazemos, de uma pedagogia. Ora,

\footnotetext{
${ }^{26}$ Symp. 218d

${ }^{27}$ ROMILLY. J. Alcibíades. Os perigos da ambição. Ediouro, 1996. P. 17

${ }^{28}$ Id. 1996

${ }^{29}$ Symp. 218d
}

Cadernos Cajuína, V. 3, N. 1, 2018, p. 12 - 23.

ISSN: 2448-0916 
torna-se evidente pelo testemunho do discurso de Alcebíades que há nessa relação uma alteração de papeis, uma inversão. Mas parece-nos que já é próprio do Sócrates platônico inverter as relações sociais do mundo em que vivia, inverter não no sentido de causar uma desordem mas de denunciar as aparências e de submeter todas as ações ao domínio da inteligência: No Simpósio a inversão é basicamente esta: Sócrates enquanto amante torna-se desejável por Alcibíades. A relação entre as personagens pode ser lida a partir dessa inversão de papéis.

De maneira geral, a relação era submetida às regras da pederastia, e portanto, pedagógica, e dentre as regras máximas o mestre devia conquistar e agradar seu discípulo. Aí está a o problema da educação de Alcibíades, pois o discípulo tenta conquistar o mestre. Relata Alcibíades que apesar de suas investidas, enquanto discípulo, Sócrates como mestre mantinha-se sempre sóbrio e irredutível em suas ações: medindo força no ginásio ${ }^{30}$, jantando e dormindo juntos ${ }^{31} \mathrm{e}$ mesmo julgando Sócrates como, dentre os apaixonados, o único digno dele. ${ }^{32} \mathrm{~A}$ principal alegação de Alcebíades, e aqui isto contribui para definição de um Sócrates que inverte as relações, é que Sócrates torna-se desejável. Nisto, é maravilhoso o fato de que o amor de Sócrates provoca, ensina e ao mesmo tempo mantém a tensão do desejo em manter próximo de si o Belo, o que de fato, parece "um segredo de um bom sedutor."33

\section{CONCLUSÃO}

Ainda durante a fala de Sócrates- Diotima, vemos, ainda falar sobre a natureza do amor, a seguinte passagem: "é o seguinte, disse: quem quiser percorrer nessas questões o verdadeiro caminho, deve começar desde a infância a procurar belos corpos." ${ }^{34}$ Ou seja, dentre os conteúdos ensinados e aprendidos pelo grego, parece que um deles é o amor.

Dentro da ética platônica, submeter todas as partes da alma à razão através da Paideia, e, portanto, ordenar o amor enquanto dimensão que leva o homem a

\footnotetext{
${ }^{30}$ PLATÃO. Symp. 217c

${ }^{31}$ PLATÃO Symp.217d

${ }^{32}$ PLATÃO. Symp. 218d

${ }^{33}$ PARMA. 2011. p. 168.

${ }^{34}$ Symp. $210 \mathrm{~A}$
} 
relacionar-se com todas as coisas, inclusive com o próprio conhecimento é um caminho ideal para o processo de auto aprimoramento, priorizado pela pederastia grega e pela filosofia de Platão.Com isso respondemos à segunda questão: $O$ chamado 'amor platônico' não distancia-se do real, mas lhe é próximo pela sua aplicabilidade, e o Eros do Simpósio contribui para falarmos da complexidade que é o amor e o desejo para o ser humano.

O amor pode ser experimentado através do convívio, e dentro das regras da pederastias, através do cultivo de normas morais e viris, porém não pode-se desprezar, nessa "pedagogia" a experiência do aprendiz, a forma como ele se relaciona com o conteúdo ensinado. A questão de Alcebíades mostra claramente como faltou a ele a vivência prática do que foi ensinado, e levanta a questão que já ouvimos diversas vezes nas salas de aula: o melhor dos mestres não garante o aprendizado do aluno.

Por fim, respondemos a questão central do trabalho: amor platônico ou amor em Platão. Aqui podemos afirmar que a segunda expressão explica a primeira e a esclarece. Se o amor platônico é sexualizado e irreal, o conceito de Eros do banquete e mais especificamente, a relação de Sócrates e Alcebíades no Simpósio nos diz que ele é bastante real e prático e preza por uma dessexualização afim de ascender ao Verdadeiro amor, ao amor à Sabedoria comumente chamada de 'scala amoris', a escala ascendente do amor em direção à verdade. Noutras palavras, diferente do que afirma o senso comum, o que chama-se comumente de amor platônico é na verdade um amor que conduz os envolvidos na relação amorosa à virtude, ao autoaprimoramento de si mesmo, à uma constante revisão da própria existência. O amor não pode fazer-nos mal, entristecer-nos, frustrar-nos, se o faz é porque não é verdadeiro amor, o fato de uma correspondência ou não, não caracteriza o amor na filosofia de Platão, o amor platônico: se falarmos de amor em Platão, devemos analisar a proposta do autor em mostrar que, apesar de perigoso, o amor é um caminho para o Bem.

\section{REFERÊNCIAS}

ARAÚJO JUNIOR. Anastácio Borges de. Eros, direzione e efetti. In: Il simpósio di Platone: um banchetto di interpretazioni. Napoli, Lofredo editore. 2013.

BRÈS, Yvon. La Psychologie de Platon. 2 ed. Paris: PUF,1973. 
DE LA TORRE. Emílio Suárez. En torno al banquete de Platón. Humanitas vol. LIV (2002) 63-100.

DOVER, K. J. A homossexualidade na Grécia antiga. Trad. L. S. Krausz. São Paulo: Nova Alexandria, 1994.

FERRARI, F. (2012). "Eros, Paideia e Filosofia: Sócrates entre Diotima e Alcibíades". Archai n. 9, jul-dez 2012, pp. 65-116.

FOULCALT. M. História da sexualidade: vol.2 O uso dos prazeres. São Paulo: Ed. Graal, 2010.

GOERGEN. Pedro. De Homero e Hesíodo ou das origens da filosofia e da educação. Pro-Posições, v. 17, n. 3 (51) - set./des. 2006.

HADOT, P. Ejercicios espirituales y filosofia antigua. Siruella, Madri. 2006.

JAEGER, Werner. Paideia: a formação do homem grego. 5ae edição. São Paulo: Martins fontes, 2011.

PARMA, Lorena Rojas. De amore: Sócrates y Alcibíades en el Banquete de Platón. ARETÉ. Revista de Filosofía. Vol. XXIII, N 1, 2011 pp. 159-186.

MAS. Salvador. Eros platónico y amor a los muchachos. ISEGORÍA, N. 48, enerojunio, 2013, 245-268, ISSN: 1130-2097 doi: 10.3989/isegoria.2013.048.14. MAZEL, J. As metamorfoses de Eros. O amor na Grécia antiga. São Paulo: Martins fontes, 1988.

NUSSBAUM Martha C. A fragilidade da bondade. Fortuna e ética na filosofia grega. São Paulo: Martins fontes, 2009.

PEREZ. Daniel Omar. O amor e a procura de si. In. Revista Ciência e vida: Filosofia. Escala. Ano VIII n. 99 Outubro 2014.

PLATÃO. Simpósio. Tradução de Carlos Alberto Nunes. - 3aㅗ ed. - Belém: ed. UFPA 2011.

ROBIN, Léon. La théorie platonicienne de l’amour. Paris :PUF, 1964.

ROMILLY, Jacqueline. Alcibíades: os perigos da ambição. São Paulo: Ediouro, 1996.

ROWE, C. "The Symposium as a Socratic Dialogue". In Lesher et alii. 2006.

VLASTOS, Gregory. The Individual as an object of Love in Plato. In. Platonic Studies, Princeton, 1973. 